César Landa Arroyo ${ }^{(*)}$

\title{
El proceso de amparo en América Latina
}

\author{
"ES PRECISAMENTE LA JURISPRUDENCIA LA QUE HA IDO SISTEMATIZANDO LOS DERECHOS \\ FUNDAMENTALES DE TUTELACONSTITUCIONAL; ASÍ, SE RECONOCEN DERECHOS FUNDAMENTALES \\ NO SOLO CONSTITUCIONALES, SINO TAMBIÉN DE CONFIGURACIÓN INTERNACIONAL, LEGAL E \\ INCLUSO JURISPRUDENCIAL".
}

\section{Premisas}

El amparo constitucional es una institución procesal producto del tránsito del Estado de Derecho basado en la ley hacia un Estado de Derecho basado en la Constitución. Esta innovación aparece modernamente cuando la vieja noción de los derechos públicos subjetivos de creación legislativa, que reconocía los derechos y libertades en los códigos y otorgaba al Poder Judicial su tutela, se transforma en la noción de los derechos fundamentales consagrados en la Constitución, los cuales requieren defensa y protección a través de procesos constitucionales como el amparo, a ser resueltos por tribunales constitucionales (España 1931, Alemania 1949)(1). Ello sin perjuicio que en sus antecedentes europeos existiera un recurso de queja, por ejemplo en la Constitución Suiza de 1848

No obstante, es recién en las postrimerías de la Segunda Guerra Mundial que el Estado Constitucional de Derecho se afirma en un conjunto de valores y principios democráticos que otorgan a los derechos fundamentales una naturaleza no sólo subjetiva e individual, sino también un carácter objetivo como garante de la persona humana y de su dignidad. Así, el proceso de amparo cumple tanto con tutelar el derecho individual, como también los valores institucionales en que se asienta dicho proceso constitucional; tareas que cumplen los Tribunales Constitucionales o queda reservada para las Cortes Supremas, en última instancia, como intérpretes supremos de la Constitución y guardianes de los derechos fundamentales.

(*) Ex-Presidente del Tribunal Constitucional del Perú. Profesor de Derecho Constitucional en la Pontificia Universidad Católica del Perú y en la Universidad Nacional Mayor de San Marcos.

(1) LEIBHOLZ, Gerhard. Problemas fundamentales de la democracia moderna. Madrid: Instituto de Estudios Políticos, 1971. pp. 145-174; asimismo, DE VEGA, Pedro. Estudios político constitucionales. México: Universidad Nacional Autónoma de México, 1987. pp. 283-309. 


\section{El proceso de amparo en América Latina}

En América Latina, el amparo entendido como proceso constitucional no es de larga data. Se incardina en los procesos de modernización democráticos a través de las nuevas constituciones o reformas constitucionales del siglo XX (México 1917, Brasil 1934, Perú 1979, Colombia 1992, Argentina 1994)(2). No obstante, es del caso precisar que desde la época de los Imperios Español y Portugués, existieron el amparo colonial y la seguridad real, respectivamente. Pero, una vez asentada la vida republicana, durante el siglo XIX bajo la influencia sajona se fue incorporando el interdicto del hábeas corpus en nuestra región, desde donde luego se fue consagrando el juicio o recurso de amparo; sin perjuicio del amparo mexicano de la Constitución de 1857 o la de Yucatán de 1840.

Sin embargo, el desarrollo contemporáneo de la justicia constitucional en torno a los Tribunales Constitucionales o Cortes Supremas ha hecho del proceso de amparo el mejor indicador para caracterizar el estado de la tutela de los derechos fundamentales en la región latinoamericana. Si bien el amparo ha surgido como un instrumento procesal de fortalecimiento de dichos derechos, también es cierto que en la actual hora democrática existen déficits de institucionalidad estatal y social que llevan a concebir al amparo como un "noble sueño" o como "una pesadilla"(3).

Es un "noble sueño" en la medida que los jueces deben aplicar el Derecho existente y no crear nuevas normas aún cuando la Constitución y las leyes no ofrezcan una regla determinada para resolver un amparo. Ello supone partir de una noción positivista y normativista del proceso de amparo, que se encuentra regulado por la norma constitucional y legal, delimitando la función interpretativa del juez constitucional y los alcances de sus sentencias; lo cual usualmente se corresponde con una concepción individualista de los derechos que protege el amparo y, en consecuencia, obliga

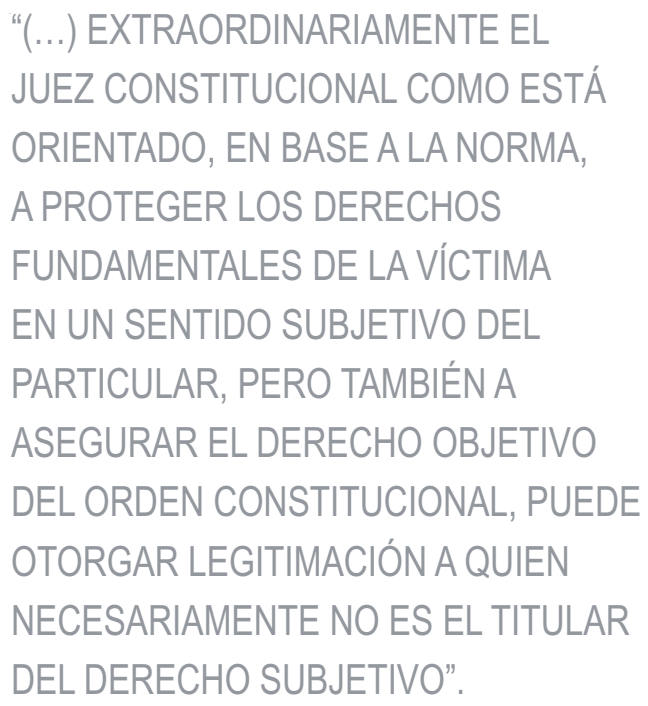

al juez a pronunciarse exclusivamente sobre el petitorio de la demanda -principio de congruencia-, convirtiendo al amparo en un proceso formalista y subjetivo(4).

Pero, el amparo también se convierte en "una pesadilla" cuando los jueces y tribunales constitucionales, para declarar el derecho fundamental demandado, crean una norma jurídica que permite resolver la pretensión planteada; aunque no se trate de inventar una norma compatible con la Constitución, sino más bien de identificar la que razonablemente se derive de una disposición constitucional, lo que supone que la norma constitucional sea concebida también como norma histórica y

(2) LANDA, César. La vigencia de la Constitución en América Latina. En: LANDA, César y Julio FAÚNDEZ. Desafíos constitucionales contemporáneos. Lima: Pontificia Universidad Católica del Perú, Fondo Editorial, 1996. pp. 13-23.

(3) HART, Herbert. Una mirada inglesa a la teoría del derecho americana: la pesadilla y el noble sueño. En: AUTORES VARIOS. El ámbito de lo jurídico. Barcelona: Crítica, 1994. pp. 327-350.

(4) DÍEZ-PICAZO, Ignacio. Reflexiones sobre el contenido y efectos de las sentencias dictadas por el Tribunal Constitucional en recursos de amparo. En: DIEZ-PICAZO, Ignacio Díez-Picazo y Juan XIOL RíOS. La sentencia de amparo constitucional. Actas de la I Jornada de la Asociación de Letrados del Tribunal Constitucional. Madrid: Centro de Estudios Constitucionales, 1996. pp. 17-74; asimismo, MONTERO AROCA, Juan (coordinador). Proceso e ideología: un prefacio, una sentencia, dos cartas y quince ensayos. Valencia: Tirant lo Blanch, 2006. p. 438. 


\section{César Landa Arroyo}

social, permitiendo una labor interpretativa y argumentativa del juez en aras de la tutela del derecho violado, de acuerdo con la realidad de la que emana; reconociendo también derechos colectivos, ampliando la legitimidad de las partes y desarrollando diversos tipos de sentencias y mandatos incluso con efectos generales o normativos, con alcances no sólo para las partes, sino también para todos. Ello configura un estatus del juez que lo convierte en una suerte de juez-pretoriano y al amparo en un proceso garantista y objetivo ${ }^{(5)}$.

Ello se debe a que "cada concepción de la Constitución lleva consigo una concepción del procedimiento, como toda concepción del procedimiento lleva consigo una concepción de Constitución. No existe un prius ni un posterius, sino una recíproca implicación"(6). Por ello, estas dos concepciones jurídicas del proceso constitucional nos recuerdan que la Constitución y el Derecho Procesal se colocan en una línea de tensión en función de la tutela subjetiva de los derechos fundamentales y la tutela objetiva de la Constitución; tensión en la cual el juez constitucional adopta diversas posturas, a partir de la aplicación y/o interpretación normativa ${ }^{(7)}$, que se pone en evidencia en la praxis jurisprudencial y los desafíos de algunos temas centrales del amparo en Argentina, Brasil, Colombia, México y Perú, entre otros países, que presentamos a continuación.

\section{Objeto de protección (tutela de los derechos fundamentales)}

El amparo tiene como finalidad tutelar los derechos fundamentales violados; pero, "los derechos fundamentales se presentan con su 'doble carácter'; como derechos subjetivos y como elementos de un ordenamiento objetivo"(8); lo cual hace que el objeto de protección constitucional asuma diferentes formas de concebir los derechos materia de protección. Es precisamente la jurisprudencia la que ha ido sistematizando los derechos fundamentales de tutela constitucional; así, se reconocen derechos fundamentales no sólo constitucionales, sino también de configuración internacional, legal e incluso jurisprudencial( ${ }^{(9)}$.

a) Protección amplia.- En Argentina se concibe que todo derecho, distinto de los que tutela el habeas corpus y el habeas data, puede ser amparado con prescindencia de su fuente normativa constitucional, lo que supone que cualquier derecho de origen legal, administrativo e internacional, que pueda ser reconducido a la Constitución es materia de tutela del amparo ${ }^{(10)}$. Más aún, la protección alcanza a derechos individuales y colectivos, como en el "Caso del Corralito Financiero" que tuteló derechos de los consumidores y usuarios, como también a derechos

(5) XÍOL-RÍOS, Juan Antonio. Algunas reflexiones al hilo de la ponencia de Ignacio Díez-Picazo "reflexiones sobre el contenido y efectos de las sentencias dictadas en procesos constitucionales de amparo”. En: DIEZ-PICAZO, Ignacio y Juan Xiol-Ríos. Op. cit:; pp. 75-107; asimismo, LOPES SALDANHA, Jania Maria y Angela ARAÚJO ESPINDOLA. A Jurisdicão constitucional e o caso da ADI 3510. En: Anuario de Derecho Constitucional Latinoamericano. Uruguay: Konrad Adenauer Stiftung, 2009. pp. 311-328.

(6) ZAGREBELSKY, Gustavo. ¿Derecho Procesal Constitucional? Y otros ensayos de justicia constitucional. México: FUNDAP, 2004. p. 18.

(7) ZAGREBELSKY, Gustavo. La giustizia costituzionale. Milano: II Mulino, 1977. pp. 39-69.

(8) HÄBERLE, Peter. El recurso de amparo en el sistema germano-federal de jurisdicción constitucional. En: GARCÍA BELAUNDE, Domingo y Francisco FERNÁNDEZ SEGADO (coordinadores). La jurisdicción constitucional en Iberoamérica. Madrid: Dykinson, 1997. p. 256.

(9) RUBIO LLORENTE, Francisco. La configuración de los derechos fundamentales en España. En: Liber Amicorum Héctor Fix Zamudio. San José de Costa Rica. Secretaría de la Corte Interamericana de Derechos Humanos. Volumen II, 1998. pp. 1329-1343.

(10) SAGÜÉS, Néstor. El amparo argentino y su reforma. En: ABAD YUPANQUI, Samuel y Pablo PÉREZ TREMPS (coordinadores). La reforma del proceso de amparo: la experiencia comparada. Lima: Palestra, 2009. pp. 24-26. 
explícitos o implícitos ${ }^{(11)}$. En el Perú, todo derecho distinto de los que tutela también el hábeas corpus, el hábeas data y el proceso de cumplimiento, es protegido por el amparo; además, pueden ser derechos civiles, políticos, económicos y sociales, de origen constitucional -nominados o innominados, como el derecho a la verdad de un detenido desaparecido, en el Caso Villegas Namuche (Expediente 2488-2002-HC/TC)- o de configuración legal o administrativa y, en todo caso, derivados de los tratados internacionales. En la nueva Constitución de la República Dominicana de 2010, se reconoce al amparo en términos similares al modelo argentino y peruano; no obstante, mediante el proceso de amparo en el Perú se tutela sólo el contenido constitucional directamente protegido del derecho invocado.

b) Protección intermedia.- En Colombia la acción de tutela protege los derechos fundamentales de manera residual y subsidiaria (Sentencias T-001-97, T-441/93 y T-003/92), frente a la acción u omisión de autoridad o particular. Asimismo, al igual que en Colombia, en Venezuela y Ecuador se protegen derechos que la Constitución y los tratados consagran, pero no los creados por una norma legal. Por su parte, la Corte Constitucional colombiana ha establecido que la revisión de las sentencias de tutela provenientes del Poder Judicial es "una atribución libre y discrecional de la Corporación para revisar los fallos de tutela que sean remitidos por los diferentes despachos judiciales, con el fin de unificar la jurisprudencia sobre la materia y de sentar bases sólidas sobre las que los demás administradores de justicia se puedan inspirar al momento de pronunciarse sobre los derechos fundamentales"(12).

Asimismo, la Corte ha delimitado seis tipos de derechos fundamentales a tutelar mediante la acción de tutela: (i) los derechos civiles y políticos de aplicación inmediata; (ii) los derechos fundamentales del Título II, Capítulo I.; (iii) los derechos de lo niños, vida, integridad, salud, seguridad social, alimentación equilibrada, nombre, nacionalidad, a tener familia, al cuidado y amor, educación, cultura, entre otros, que estén establecidos en las leyes y tratados internacionales; (iv) los derechos fundamentales innominados, como el mínimo vital; (v) los derechos fundamentales conexos, como a la verdad, justicia y reparación (Sentencia T-821-2207); y, (vi) los derechos fundamentales provenientes de los tratados de derechos humanos y del derecho internacional humanitario ${ }^{(13)}$.

c) Protección limitada.- En Brasil el mandado de segurança individual protege los derechos constitucionales líquidos y ciertos $^{(14)}$ cuando son violados por acto u omisión ilegal o proveniente del abuso del poder, tal como lo dispone la Ley Federal 12016 del 7 de agosto de 2009. Antes, además, los derechos tutelados debían ser incontrastables, es decir, no interpretables. Ahora, si bien pueden ser objeto de interpretación, en cambio deben estar acompañados de prueba documental pre constituida (Súmula 625 STF).

En definitiva, el derecho debe estar previsto en una norma legal y debe ser probado de forma indubitable; salvo en materia tributaria donde se dejan márgenes de apreciación judicial; en efecto no existen en esa circunstancia actos discrecionales absolutamente inmunes

(11) CORTE SUPREMA DE JUSTICIA DE LA NACIÓN. Emergencia económica II. Buenos Aires: Secretaria de Jurisprudencia, 2009. pp.28-32.

(12) JULIO ESTRADA, Alexei. Corte Constitucional (Colombia). En: FERRER MAC-GREGOR, Eduardo (coordinador). Crónica de Tribunales Constitucionales en Iberoamérica. Argentina: Marcial Pons, 2009. p. 135.

(13) BOTERO, Catalina. La acción de tutela en Colombia: Ajustes necesarios y cautelas indispensables. En: La reforma del proceso de amparo: la experiencia comparada. Op. cit.; pp. 133-140.

(14) GÖES FERNANDES, Gisele. El abuso del 'mandato de seguridad' en la experiencia brasileña. En: La reforma del proceso de amparo: la experiencia comparada. Op. cit.; pp. 46-49. 


\section{César Landa Arroyo}

al control jurisdiccional (STJ. Mandado de Segurança 6.166DF) ${ }^{(15)}$. Asimismo, la Constitución reconoce el mandado de segurança colectivo para tutelar derechos difusos y colectivos que puedan ser vulnerados por actos y leyes. No obstante, existe una fuerte polémica sobre la exigibilidad judicial de los derechos sociales y el papel del Poder Judicial en la tutela de los mismos.

En México, en cambio, las llamadas garantías individuales de igualdad, libertad, seguridad jurídica y de propiedad, que se basan en la dignidad del hombre son protegidas en el juicio de amparo; por eso existen amparo de la libertad -hábeas corpus-; amparo contra resoluciones judiciales -recurso de casación-; amparo contra leyes -declara la inconstitucionalidad de una norma legal-; amparo como un proceso contencioso administrativo; $y$, amparo social para proteger derechos agrarios, que incluye la protección de garantías sociales, pero no de derechos de carácter colectivo o difuso, ni implícitos, ni derivados de tratados internacionales, proscritos en el clásico juicio de amparo mexicano. En todos estos casos, el juicio de amparo cumple la función principal de control de la constitucionalidad, en la medida que se tutela a la persona como individuo de las relaciones jurídicas entre el gobernado y el Estado y las autoridades ${ }^{(16)}$.

\section{Objeto del control (acto lesivo)}

En todo proceso de amparo se debe delimitar no sólo el derecho fundamental violado, sino también determinar el acto lesivo materia de control constitucional; lo cual lleva a identificar quién y con qué se puede agraviar los derechos fundamentales del afectado. Al respecto, clásicamente los derechos como son oponibles al poder, sólo cabe que se demanden a la autoridad pública -eficacia vertical-, sin embargo, contemporáneamente también son oponibles a otro particular -eficacia horizontal-, sólo que la eficacia puede ser inmediata dada la fuerza normativa constitucional $\mathrm{o}$, mediata en la medida que las normas intermedias hayan precisado su naturaleza jurídica y los actos lesivos materia de protección ${ }^{(17)}$. Por ello, aquí también se pueden clasificar los distintos tipos de control.

a) Control amplio.- En Argentina abarca todo acto u omisión de autoridad pública o particular. Se entiende como acto a la vía de hecho, actos propiamente, acciones, decisiones, órdenes y actos jurídicos, por ejemplo. La omisión genera una orden judicial para que se restablezca el derecho en un plazo, o en la ejecución del hecho omitido. El acto lesivo puede ser emitido por los siguientes:

a.1. Autoridad pública, entendida como la autoridad, funcionario, particular en ejercicio de función pública.

a.2. Poder Legislativo, al dictar actos administrativos, dictámenes de comisiones parlamentarias, leyes autoaplicativas -es decir, que afectan un derecho directamente sin requerir norma o acto intermedio aunque con la reforma constitucional de 1994 también cabe contra leyes no autoaplicativas de cumplimiento obligatorio o discrecional- y cuando hay amenaza de emisión de norma programática simple, es decir proyecto de leyes y ante la omisión legiferante inconstitucional (Casos de la "Pesificación" y del "Corralito Financiero", en los fallos: Rinaldi, Massa, Smith, Bustos, Galli, entre otros) $^{(18)}$.

(15) AFONSO DA SILVA, José. El mandamiento de seguridad en Brasil. En: FIX-ZAMUDIO, Héctor y Eduardo FERRER MACGREGOR (coordinadores). El Derecho de Amparo en el mundo. México: Porrúa, 2006. pp. 129-132.

(16) FIX-ZAMUDIO, Héctor y Eduardo FERRER MAC-GREGOR. El derecho de amparo en México. En: El Derecho de Amparo en el mundo. Op. cit.; pp. 472-478.

(17) DE VEGA GARCÍA, Pedro. La eficacia horizontal del recurso de amparo: el problema de la Drittwirkung der Grundrechte. En: Derecho. Número 46. Lima: Pontificia Universidad Católica del Perú, Fondo Editorial, diciembre 1992. pp. $357-375$.

(18) MANILI, Pablo Luis. Corte Suprema de Justicia de la Nación (Argentina). En: Crónica de Tribunales Constitucionales en 


\section{El proceso de amparo en América Latina}

a.3. Poder Judicial, cabe el control de los actos jurisdiccionales cuando no hay otro remedio procesal(19). Cabe señalar que en el proceso de amparo cabe solicitar una medida cautelar y también cabe el amparo contra el amparo.

En el Perú también procede el amparo contra el hecho u omisión, por parte de cualquier autoridad, funcionario o persona que viole derechos fundamentales -distintos a los protegidos por el hábeas corpus, el hábeas data y el de cumplimiento-; sin embargo, prima facie no cabe contra normas legales ni resoluciones judiciales emanadas de un proceso regular. De manera extraordinaria, el Código Procesal Constitucional y la jurisprudencia del Tribunal Constitucional han precisado que sí procede contra:

a.1. Actos jurisdiccionales, en particular contra resoluciones firmes y en la medida que el hecho y el petitorio se refieran a un derecho con contenido directamente protegido en la Constitución, y, que no haya una vía igualmente satisfactoria. En este aspecto, es similar a Venezuela, Guatemala, Honduras y Panamá, con la salvedad que en estos países el control de las resoluciones judiciales excluye a las decisiones de las Corte Supremas ${ }^{(20)}$.

a.2. Actos del gobierno y de la administración pública, incluso contra actos discrecionales como el indulto (Caso Jaililie Awapara, Expediente 4053-2007-PHC/ TC) o cuestiones políticas como la declaratoria de un estado de excepción.

a.3. Actos parlamentarios, como las leyes autoaplicativas y los actos no legislativos que afecten derechos fundamentales, como fue el caso de los magistrados constitucionales destituidos arbitrariamente por el Congreso, al declarar inconstitucional la ley de la reelección del Presidente Fujimori en 1997 (Expedientes 0340-1998-AA/ TC y $358-1998-A A / T C)^{(21)}$.

a.4. Actos particulares, en la medida que también las relaciones jurídicas entre los particulares están sujetas a la Constitución y no sólo a la ley, sobretodo si son vínculos asimétricos entre las partes, en materia laboral, de salud, del consumidor, etc. En el amparo es procedente solicitar una medida cautelar y también es factible, aunque infrecuente, que se produzca un proceso de amparo contra otro amparo, siempre que el primero no haya sido expedido por el Tribunal Constitucional.

Asimismo, en Colombia procede la acción de tutela contra cualquier actuación u omisión de cualquier autoridad pública o de particulares. En consecuencia, se puede interponer contra: (i) Autoridad administrativa, tal es el frecuente caso en materia de pensiones de jubilación y de salud; (ii) Actos judiciales lo que ha generado muchas veces el rechazo de la Corte Suprema y del Consejo de Estado, dando lugar al llamado "choque de trenes"; (iii) Particulares, donde la jurisprudencia ha distinguido entre quien: (iii.1) presta función pública, (iii.2) cuando quien demanda está en situación de

Iberoamérica. Op. cit.; pp. 38-44; donde se da cuenta de los fallos relativos a las medidas gubernamentales financieras y bancarias que han generado más de cien mil amparos contra dichas medidas; motivo por el cual la Corte Suprema ha tenido defensores pero más detractores de sus fallos, por estimar el derecho de los justiciable dentro de los marcos de la estabilidad económica-financiera, antes que de la estabilidad jurídica de los agraviados.

(19) SAGÜÉS, Néstor. Compendio de derecho procesal constitucional. Buenos Aires: Astrea, 2009. pp. 425-436; asimismo, véase CORTE SUPREMA DE JUSTICIA DE LA NACIÓN. Emergencia económica II. Op. cit.; pp. 28-32, 39-73, 83-94, 129-144, $230-243$.

(20) BREWER-CARÍAS, Allan. Ensayo de síntesis comparativa sobre el régimen del amparo en la legislación latinoamericana. En: Revista Iberoamericana de Derecho Procesal Constitucional. Número 9. Argentina: Porrúa. pp. 311-321.

(21) LANDA, César. Tribunal Constitucional y Estado Democrático. Tercera edición. Lima: Palestra, 2007, pp. 796-804. 


\section{César Landa Arroyo}

subordinación, (iii.3) cuando el demandado es un medio de comunicación social y (iii.4) cuando la conducta del particular afecte grave y directamente el interés colectivo ${ }^{(22)}$.

b) Control Intermedio.- En México cualquier hecho voluntario y conciente, negativo y positivo, desarrollado por un órgano del Estado, consistente en una decisión o en una ejecución o en ambas conjuntamente, que produzcan una afectación de situaciones jurídicas o fácticas dadas, y que se impongan imperativamente da lugar al juicio de amparo. Así, cabe el amparo contra:

b.1. Leyes inconstitucionales que se inaplican al caso concreto sin declaración ni efecto general de invalidez de la ley.

b.2. Resoluciones judiciales, previo examen de legalidad sólo de las decisiones firmes o de última instancia, con el límite de las resoluciones de la Suprema Corte de Justicia; también procede contra procesos extraordinariamente por violaciones durante el juicio, cuando se afecte el derecho de defensa del quejoso y contra resoluciones de fondo de sentencias y laudos arbitrales.

b.3. Actos y resoluciones administrativos que sean definitivos de la Administración Pública, cuando afecten derechos de un particular. No obstante, no cabe un juicio de amparo en materia electoral.

Las personas privadas no pueden pedir amparo contra actos de otros particulares, salvo que en su calidad de tercero pueda verse perjudicado -sujeto pasivo indirecto-; el juicio de amparo prevé la posibilidad de dictar medidas cautelares, suspendiendo los actos reclamados ${ }^{(23)}$. c) Control limitado.- En Brasil el mandado de segurança se incoa contra actos de la autoridad pública y no cabe contra actos de un particular ${ }^{(24)}$. Pero, no puede demandarse contra actos administrativos si existe un recurso administrativo con efecto suspensivo, independiente de la caución. Tampoco procede contra decisiones judiciales, salvo en el caso de una sentencia judicial que sea viable suspender su eficacia -en tanto afecte un derecho líquido y concreto- que además sea promotora de abusos, desmanes o ilegalidades, siempre que no hubiere otro recurso ordinario disponible. El mandado de segurança no procede contra leyes, proyectos de leyes, ni actos administrativos, salvo que por abuso de poder tengan efectos concretos, aunque contra los actos administrativos de origen judicial se discute su procedencia. Cabe señalar también que del total de la carga procesal del Supremo Tribunal Federal los mandatos de seguridad sólo fueron el $0,69 \%$ en el año 2007; no obstante su incremento en los tribunales inferiores ${ }^{(25)}$.

\section{Sujetos del proceso (legitimación)}

Clásicamente se ha identificado el derecho subjetivo y la acción, de aquí que sólo podía ejercitar la acción quien había sido vulnerado en un derecho. Así, el proceso de amparo en principio ordinariamente ha supuesto que

(22) ORTIZ, Julio César. La acción de tutela en la Carta Política de 1991. El derecho de amparo y su influencia en el ordenamiento constitucional de Colombia. En: FIX-ZAMUDIO, Héctor y Eduardo FERRER MAC GREGOR. El Derecho de Amparo en el mundo. Op. cit.; 237-240; asimismo, BOTERO, Catalina. La acción de tutela en Colombia: Ajustes necesarios y cautelas indispensables". Op. cit; ; pp. 142-145.

(23) CARPIZO, Jorge, José COSSIO y Héctor FIX-ZAMUDIO. La jurisdicción constitucional en México. En: La jurisdicción constitucional en Iberoamérica. Op. cit.; pp. 762-771 y 779-785.

(24) PINTO FERREIRA, Luiz. Os instrumentos processuais protetores dos direitos no Brasil. En: La jurisdicción constitucional en Iberoamerica. Op. cit.; pp. 427-429.

(25) AFONSO DA SILVA, Virgilio. Supremo Tribunal Federal (Brasil). En: Crónica de Tribunales Constitucionales en Iberoamérica. Op. cit.; p. 95. 


\section{El proceso de amparo en América Latina}

el titular del derecho fundamental violado es el titular de la acción; sin embargo, extraordinariamente el juez constitucional como está orientado, en base a la norma, a proteger los derechos fundamentales de la víctima en un sentido subjetivo del particular, pero también a asegurar el derecho objetivo del orden constitucional, puede otorgar legitimación a quien necesariamente no es el titular del derecho subjetivo(26), como se puede apreciar a continuación:

a) Legitimación amplia.- En Colombia la acción de tutela expresa una relación jurídica procesal abierta en la medida que:

a.1. Legitimación activa.- Cualquier persona natural o persona jurídica afectada en sus derechos directa o indirectamente en sus integrantes (Sentencia T-411-99) puede interponer la acción de tutela, directamente o mediante apoderado judicial; cabe entender que la titularidad alcanza a los menores de edad y a los extranjeros en tanto sujetos de derechos fundamentales violados o amenazados, en el caso de los menores cualquier persona también puede demandar para proteger sus derechos; las comunidades indígenas también son titulares de la acción de tutela en defensa de sus derechos fundamentales reconocidos en la Constitución. La acción de tutela se puede demandar directamente o mediante abogado; también tienen legitimidad para demandar el Defensor del Pueblo, los Personeros Municipales y la ley autoriza a la agencia oficiosa la defensa judicial cuando el afectado no pueda promover su propia defensa; se reconoce el rol de apoyo procesal a los "amigos de la corte" -amici curiae-.

a.2. Legitimación pasiva.- Se interpone contra cualquier autoridad pública o particulares ${ }^{(27)}$.

Cabe también el amparo contra particulares en Bolivia, Chile, República Dominicana, Paraguay, Uruguay y Venezuela, entre otros países.
EL AMPARO NO ESTÁ PREVISTO

PARA ESTABLECER SANCIONES O

INDEMNIZACIONES POR DAÑOS Y

PERJUICIOS, PESE A LA DETERMINACIÓN

DEL ACTO LESIVO Y DEL RESPONSABLE.

TAMPOCO EXISTE PLAZO PARA EL

CUMPLIMIENTO DE LA SENTENCIA,

\section{SINO QUE QUEDA LIBRADO A CRITERIO}

\section{DISCRECIONAL DEL TRIBUNAL".}

En Perú la relación de los sujetos procesales proviene no sólo de quien es el agraviado y de quien es el agraviante, sino que también gozan de legitimación para obrar terceras personas e instituciones, dado el carácter flexible del amparo sobretodo en la tutela de derechos difusos; ello en la medida que opera la presunción procesal iuris tantum favorable a la víctima:

a.1. Legitimación activa.- La ejerce la persona natural, peruana o extranjera, asimismo, las personas jurídicas privadas, peruanas o extranjeras, en los derechos constitucionales que les sean afectados o amenazados. Sin embargo, surge la cuestión si la legitimidad alcanza a las personas jurídicas de derecho público. Al respecto, la jurisprudencia del Tribunal Constitucional ha establecido que sí les corresponde accionar el amparo, pero sólo en relación con los derechos fundamentales referidos al debido proceso y a la tutela jurisdiccional

(26) MONTERO AROCA, Juan, Juan GÓMEZ COLOMER, Alberto, MONTÓN REDONDO y Silvia BARONA VILAR. Derecho Jurisdiccional. II Proceso Civil. Novena edición. Valencia: Tirant lo Blanch, 2000. pp. 53-79.

(27) ORTIZ, Julio César. La acción de tutela en la Carta Política de 1991. El derecho de amparo y su influencia en el ordenamiento constitucional de Colombia. 


\section{César Landa Arroyo}

efectiva. Asimismo, la Defensoría del Pueblo tiene una legitimación institucional, pues está habilitada para la defensa de derechos individuales y sociales, así como puede interponer la acción de amparo cualquier persona cuando se trate de amenazas o violación del derecho al medio ambiente (Caso Doe Run Exp. $\mathrm{N}^{\circ}$ 2002-2006-PC/TC) u otros derechos difusos que gocen de reconocimiento constitucional, así como las entidades sin fines de lucro cuyo objeto sea la defensa de los referidos derechos. Por último, cualquier persona puede comparecer en nombre de quien no tiene representación procesal, cuando esté imposibilitada de incoar la demanda, pero una vez superado el impase deberá ratificar la actuación del procurador de oficio; cabe recibir informes y ser escuchados en la audiencia oral al amicus curiae.

a.2. Legitimación pasiva.- La ejerce la autoridad, funcionario o persona particular que viola o amenaza un derecho fundamental; sin perjuicio de ello, la defensa de los intereses del Estado en un juicio se realiza a través de los Procuradores Públicos. Pero, tanto el afectado como el demandado pueden comparecer mediante representante procesal, no es necesaria la inscripción de la representación otorgada.

En Argentina se asume el amparo como un proceso bilateral, antes que unilateral de la víctima frente al Estado y a los particulares, de modo que se regula a los sujetos procesales mediante su calidad de partes procesales, para lo cual requieren ${ }^{(28)}$.

a.1. Legitimación activa.- La demanda de amparo la puede interponer cualquier persona titular de un derecho violado -legitimatio ad causam-: pero les corresponde al defensor del pueblo y determinadas asociaciones cuando se afecten derechos como producto de la discriminación, para tutelar a los usuarios y consumidores, garantizar la competencia, proteger el medio ambiente y los derechos de incidencia colectiva. No obstante, en estos casos se asume que el promotor del amparo colectivo deber ser "afectado" de manera mediata o inmediata. El defensor del pueblo interviene no sólo a favor de los derechos sociales, económicos o ambientales violados, sino también en defensa de los derechos individuales; asimismo, un legislador está habilitado para actuar contra una norma legal, siempre que acredite la afectación concreta de un derecho. Los demandantes sean personas jurídicas de derecho privado o público requieren de representación legal para actuar y las personas naturales cuando lo requieran por ejemplo por incapacidad -legitimatio ad procesum-. Cabe la participación de los amici curie.

a.2. Legitimación pasiva.- El recurso de amparo se postula contra la autoridad pública o persona particular, sea el autor y/o responsable del acto lesivo, esto último por cuanto no siempre el autor material o ejecutor del agravio es quien decidió dicho acto lesivo (Caso Kot de 1958, con el que además se asentó jurisprudencialmente el recurso de amparo, iniciado con el Caso Siri de 1957). En todo caso interviene el Fiscal al menos cuando se debata derechos y garantías constitucionales y temas vinculados al orden público y asuntos de interés general, como los ambientales. Si bien los terceros no son parte del proceso, podrían incorporarse cuando los efectos de la sentencia les perjudiquen o beneficien.

b) Legitimación intermedia.- En México se puede calificar a las partes de la siguiente manera ${ }^{(29)}$ :

(28) SAGÜÉS, Néstor. Op. cit; pp. 507-524.

(29) FERRER MAC-GREGOR, Eduardo. La acción constitucional de amparo en México y España. México: Porrúa, 2000. pp. 228-261. 
b.1. Sujeto activo.- Es la parte actora, denominada quejoso o agraviado. Lo constituyen las personas naturales nacionales y extranjeras; los menores de edad y los sujetos a interdicción, pero mediante representante; el ofendido por un delito o las personas que tengan derecho a la reparación del daño o a exigir reparación civil; los ejidatarios -beneficiarios de la reforma agraria-, comuneros -pueblos indígenasy campesinos; los núcleos de población ejidal o comunal; las personas jurídicas privadas legalmente constituidas; las sociedades extranjeras legalmente constituidas; las personas jurídicas de derecho público cuando se encuentren en el mismo plano del particular y que el acto o la ley objeto de la controversia afecte sus intereses patrimoniales.

b.2. Sujeto pasivo.- Es la parte demandada, aquella que lesiona o pretende vulnerar las garantías individuales. Lo conforman las personas físicas; la contraparte del agraviado en un proceso -en materia distinta a la penalo persona extraña al proceso; el ofendido de un delito, o las personas que tengan derecho a la reparación del daño o a la responsabilidad civil; la persona que haya gestionado en su favor el acto administrativo impugnado; las personas jurídicas privadas en su calidad de terceros perjudicados, pero nunca como sujetos pasivos directos debido a que el juicio de amparo sólo procede contra actos de autoridad; $y$, las personas jurídicas públicas, es decir, los órganos del Estado ysus organismos descentralizados.

c) Legitimación limitada.- En Brasil el mandado de segurança puede ser interpuesto por persona naturales -nacionales y extranjeras- o jurídicas -privadas o públicas- en defensa de los derechos constitucionales líquidos y ciertos, es decir de carácter subjetivos y no intereses o derechos difusos ni colectivos, para cuya tutela existe el mandado de segurança colectivo. Sin embargo, en el caso de la titularidad de la acción por parte de los organismos públicos se requiere que tengan prerrogativas o derechos propios a defender, lo que en la práctica supone una forma de resolver un conflicto de atribuciones entre organismos públicos, llenando así una laguna normativa para buscar pacificar las controversias entre estas entidades.

Asimismo, la Constitución de 1988 reconoce el derecho de los partidos políticos con representación en el Congreso Nacional, organización sindical, entidad de grupo o asociación legalmente constituida y en funcionamiento, a ser titulares del mandado de segurança colectivo en contra de leyes y actos que en determinados supuestos vulneren derechos colectivos y difusos.

Finalmente, el Ministerio Público puede actuar como un sustituto procesal en la defensa de derechos colectivos o individuales homogéneos; asimismo, se ha incorporado el rol del amicus curiae -tercero que expresa sus puntos de vista y los efectos probables de un fallo-. No cabe contra actos de un particular, salvo que ejerza una actividad delegada de la autoridad; tampoco contra particulares. Esto también sucede en Nicaragua, Panamá y EI Salvador ${ }^{(30)}$.

\section{Sentencias (alcances del fallo)}

La sentencia de amparo tiene como finalidad tutelar los derechos fundamentales violados. En esa medida, el pronunciamiento judicial final se orienta a dejar sin efecto el acto lesivo. Sin embargo, "toda decisión judicial tiene una dimensión subjetiva, en cuanto resuelve el caso concreto, y una dimensión objetiva, en cuanto sienta un precedente que es susceptible de ser tenido en cuenta en el proceso argumentativo de sucesivas resoluciones sobre idénticos o parecidos hechos"(31), materia dilemática que

(30) PINTO FERREIRA, Luiz. Os instrumentos processuais protetores dos direitos no Brasil. Op. cit.; pp. 419-420.

(31) XIOL-RÍOS, Juan Antonio. Algunas reflexiones al hilo de la ponencia de Ignacio Díez-Picazo 'reflexiones sobre el contenido $y$ efectos de las sentencias dictadas en procesos constitucionales de amparo'. En: La sentencia de amparo constitucional. 


\section{César Landa Arroyo}

se aborda en diversos grados de intensidad según se presenta a continuación:

a) Protección amplia.- En el Perú, usualmente, la finalidad de la sentencia es la reposición al estado anterior de la violación del derecho fundamental; la sentencia no tiene naturaleza indemnizatoria, pero, cuando ello no es posible debido a que el daño se ha convertido en irreparable, el juez constitucional, luego de apreciar el agravio producido, puede pronunciarse sobre el fondo, estimando la demanda a efectos de exhortar al demandado para que no vuelva a afectar el derecho violado, pues de lo contrario, se le aplicarán las medidas coercitivas que incluye multas sucesivas y hasta la destitución, si se trata de un funcionario. La sentencia de amparo genera cosa juzgada constitucional cuando ha sido resuelta por el Tribunal Constitucional; por ello, jurisprudencial y excepcionalmente, cabe un amparo contra amparo cuando éste último, resuelto por el Poder Judicial, haya violado por ejemplo los precedentes constitucionales vinculantes (Expediente 4853-2004-PA).

De otro lado, se puede solicitar la actuación de una sentencia estimatoria de primer grado, aunque haya sido recurrida; asimismo, si la sentencia de segundo grado fuera desfavorable sólo para la víctima, ésta puede recurrir al Tribunal Constitucional en recurso de agravio y si se la deniega el Poder Judicial puede acudir directamente en queja al Tribunal. Si se reiterase el agravio declarado en una sentencia de amparo, el afectado puede recurrir a la represión de los nuevos actos lesivos homogéneos, sin necesidad de entablar un nuevo proceso de amparo.

Si bien como regla general las sentencias sólo tienen efectos entre las partes de un proceso, también el Código Procesal Constitucional (en adelante, CPC) ha previsto en el artículo VII que a la sentencia constitucional que se pronuncie sobre el fondo de la controversia se le pueda otorgar efecto normativo de carácter general -erga omnes-; esto sin perjuicio que los jueces ordinarios están vinculados a la jurisprudencia constitucional en casos similares -stare decisisprevisto en el artículo VI in fine del CPC ${ }^{(32)}$. En base a la autonomía procesal desarrollada por la jurisprudencia constitucional ${ }^{(33)}$, por un lado, el juez puede realizar de oficio el control difuso no sólo de una norma legal, sino también de una norma estatutaria privada, cuando sea necesario para resolver el caso o, por otro lado, ante la falta de certeza de una violación el juez puede disponer la supervisión periódica de una eventual afectación a futuro, sobre todo cuando se trata de los derechos a la salud por contaminación del medio ambiente(Caso Praxair Expediente 3510-2003-AA/TC).

En Colombia la sentencia del juez de tutela ordena que el demandado actúe o se abstenga de hacer algo de manera inmediata; la sentencia no tiene carácter indemnizatorio, salvo que el afectado no disponga de otro medio judicial, y la violación del derecho sea manifiesta y consecuencia de una clara y arbitraria decisión, en cuyo caso el juez puede ordenar una indemnización en abstracto.

La Corte Constitucional ha establecido que existen tres tipos de sentencias: con efectos sólo inter partes; con iguales efectos, pero también aplicable la regla establecida a casos futuros iguales; $y$, con efectos inter comunis, como por ejemplo la tutela a favor de un preso que por las condiciones carcelarias es extensible a los demás presos que estén en

Actas de las I Jornadas de la Asociación de Letrados del Tribunal Constitucional Madrid: Centro de Estudios Constitucionales, Cuadernos y Debates No 63,1996. p. 85.

(32) LANDA, César. Los precedentes constitucionales. En: Justicia Constitucional. Año III.Número 5.Lima: Palestra, enero-junio, 2007. pp. 29-69; asimismo, revisar en este volumen, entre otros, a MONTOYA, Víctor Hugo. El stare decisis constitucional. Entre la vinculación de las sentencias constitucionales y las sentencias vinculantes constitucionales. Op. cit; pp. 71-100.

(33) LANDA, César. Autonomía procesal del Tribunal Constitucional. En: Justicia Constitucional. Año II. Número. Lima: Palestra, julio-diciembre, 2006. pp. 63-95; asimismo, revisar en este volumen, entre otros, a LEÓN, Jorge. El Tribunal Constitucional y la configuración de su Derecho Procesal. Op. cit.; pp. 29-61. 
ese estado de cosas inconstitucionales (T-153/98). Adoptada la decisión judicial en la Corte, se remite la sentencia al juez de primera instancia para que se encargue de la ejecución. En caso de incumplimiento, el agraviado puede ordenar un incidente de desacato y el juez puede incluso disponer el arresto del demandado ${ }^{(34)}$.

Pero en algunas declaraciones del estado de cosas inconstitucionales, la Corte se ha reservado la competencia de la supervisión de la ejecución del fallo, por ejemplo en el caso del desplazamiento forzoso de miles de personas debido al conflicto armado interno, dispuso una serie de medidas de respeto de los derechos fundamentales de los desplazados a ser asumidas por el gobierno y, en consecuencia, ordenó que se llevasen a cabo una serie de audiencias públicas para verificar su real cumplimiento (T-025 de 2004) ${ }^{(35)}$.

b) Protección intermedia.- El complejo juicio de amparo mexicano consagra una clasificación de dichas sentencias en función de dos criterios:

b.1. El sentido en que se resuelve: sentencias que conceden el amparo; sentencias que niegan el amparo; sentencias que sobreseen el amparo; sentencias que conceden el amparo respecto de alguno o algunos de los actos reclamados y que sobreseen respecto de otro y otros actos reclamados.

b.2. Desde el punto de vista de la controversia resuelta: sobre violación de garantías individuales; sobre violación a los derechos del quejoso, derivados de la invasión de la competencia de la autoridad estatal por autoridad federal; sentencias de amparo que resuelven sobre violaciones de derechos del quejoso, derivados de la invasión de la competencia de la autoridad federal por autoridades estatales; sentencias que resuelven sobre violaciones o garantías individuales y sobre violaciones a derechos derivados del sistema de distribución competencial entre federación y Estados ${ }^{(36)}$.

Las sentencias de amparo sólo protegen al caso particular demandado y producen efectos que dependen de la clase de sentencia que se haya dictado( ${ }^{(37)}$ :

\section{b.3. Sentencia concesoria del amparo:}

1. Si el acto reclamado es de carácter positivo, la sentencia que conceda el amparo tendrá por objeto restituir al agraviado en el pleno goce de la garantía individual violada, restableciendo las cosas que guardaban antes de la violación.

2. Si el acto reclamado es de carácter positivo y el amparo ha tenido por objeto proteger al quejoso contra la invasión de facultades competenciales (artículo 103, fracciones II y III, Constitución Federal), la sentencia que conceda el amparo tendría por objeto restablecer las cosas al estado que guardaban antes de la violación de derechos derivados de la distribución de competencias entre federación y estados, restituyéndose al quejoso en el goce de esos derechos.

(34) BOTERO, Catalina. La acción de tutela en Colombia: Ajustes necesarios y cautelas indispensables.

(35) JULIO ESTRADA, Alexei. Corte Constitucional (Colombia). Op. cit.; p. 139. En efecto, debido al conflicto interno armado que existe en Colombia desde hace más de cuarenta años, se han producido más de dos millones y medio de personas desplazadas internamente; creando un estado de cosas inconstitucionales debido al reiterado incumplimiento de las autoridades públicas de un conjunto de políticas públicas que la Corte decidió monitorear en el marco de la ejecución de su sentencia T-025.

(36) FIX-ZAMUDIO, Héctor y Eduardo FERRER MAC-GREGOR. El derecho de amparo en México. Op. cit.; pp. $502-508$.

(37) COSSío, José Ramón. Juicio de amparo. Diagnóstico de posibles soluciones. En: La reforma del proceso de amparo: la experiencia comparada. Op cit.; pp. 219-220; asimismo, revisar el siguiente link disponible en web en: http//www. Bibliojuridica. org/libros/libro.htm?!=911. 


\section{César Landa Arroyo}

3. Si el acto reclamado es de carácter negativo, el efecto del amparo sería obligar a la autoridad responsable a que obre en el sentido de respetar la garantía de que se trate y a cumplir, por su parte, lo que la misma garantía exija.

4. Si el acto reclamado era de inminente aplicación y el quejoso logró impedir que se llevara a cabo mediante la suspensión, el efecto de la sentencia de amparo será que la autoridad responsable quede definitivamente impedida de consumar el acto reclamado.

5. Si se trata de una sentencia concesoria de amparo directo, que ha otorgado el amparo contra una violación de procedimiento, el efecto de la sentencia de amparo consistirá en anular la sentencia impugnada en el juicio seguido ante la autoridad responsable y anular los actos del procedimiento violatorio, debiendo reponerse el procedimiento a partir de la violación procesal y dictarse nueva sentencia por la autoridad responsable.

b.2. Sentencia de sobreseimiento: (i). Le dan fin al juicio de amparo; (ii). Se abstiene de emitir consideraciones sobre la constitucionalidad o inconstitucionalidad del acto reclamado; (iii). Deja el acto reclamado en las condiciones en que se encontraba al promoverse el juicio de amparo; (iv). Cesa la suspensión del acto reclamado; y, (v). La autoridad responsable recupera sus posibilidades de acción, de realización del acto reclamado.

b.3. Sentencia denegatoria del amparo: (i) declara la constitucionalidad del acto reclamado; (ii) finaliza el juicio de amparo; (iii) le da validez jurídica al acto reclamado; (iv) cesa la suspensión del acto reclamado; (v) deja el acto reclamado en las condiciones en que se encontraba al promoverse el juicio de amparo; (vi) permite que la autoridad responsable esté en condiciones de llevar a efecto la plena realización del acto reclamado.

En consecuencia, las sentencias de amparo sólo se extienden a la parte que lo solicitó (fórmula Otero). No obstante, desde el año 2001, existe un proyecto de reforma constitucional a fin de otorgar efectos generales a las resoluciones dictadas en las sentencias de amparo contra leyes, cuando exista cuando menos tres ejecutorias supremas uniformes ${ }^{(38)}$.

c) Protección limitada.- En Argentina la sentencia de amparo se limita a fallar concretamente sobre el petitorio demandado, de modo que no resuelve cuestiones abstractas si cesó la lesión; por ello, el fallo debe mencionar concretamente a la autoridad contra cuya decisión o acto se concede el amparo y determinar de forma precisa la conducta a cumplir con las especificaciones necesarias para su debida ejecución; aunque hay ejemplos como el del Caso Massa, en donde la Corte Suprema de Justicia de la Nación "con tono activista y en cierto punto aditivo, diseñó un criterio normativo"(39).

Asimismo, el fallo tiene efecto restitutorio del derecho violado, aunque en algún caso la jurisprudencia le ha otorgado efectos a futuro, a fin de evitar la repetición de actos lesivos así reputados en el fallo (Caso Badaro I y II, ante la falta de reglas sobre movilidad jubilatoria y Caso Río Negro ante la discriminación en la distribución periodística de la publicidad de la provincia de Neuquén) ${ }^{(40)}$. Pero, si la demanda

(38) FERRER MAC-GREGOR, Eduardo y Alfonso HERRERA GARCíA. Suprema Corte de Justicia de la Nación (México). En: Crónica de Tribunal Constitucionales en Iberoamérica. Op. cit.; pp. 330-331.

(39) BAZÁN, Víctor. La Corte Suprema de Justicia argentina se reinventa, presentándose como un tribunal constitucional. En: Cuestiones Constitucionales. Revista Mexicana de Derecho Constitucional. Número 20. México: Instituto de Investigaciones Jurídicas - Universidad Nacional Autónoma de México, enero-junio, 2009. p.29

(40) Ibid.; pp. 25-29 y 36-38. 
repite los actos lesivos y sólo cambia la fundamentación, parte de la doctrina argentina entiende que se deberá plantear un nuevo proceso de amparo.

El amparo no está previsto para establecer sanciones o indemnizaciones por daños y perjuicios, pese a la determinación del acto lesivo y del responsable. Tampoco existe plazo para el cumplimiento de la sentencia, sino que queda librado a criterio discrecional del tribunal. Asimismo, los efectos del amparo concedido son inter partes, salvo en materia ambiental y otros cuando tutelan intereses colectivos, pero no en perjuicio de los no convocados al proceso, que de lo contrario verían afectado su derecho de defensa.

Jurisprudencialmente cabe interponer un amparo contra otro amparo, en la medida que la sentencia firme declarativa de la existencia o inexistencia de la lesión, restricción, alteración o amenaza arbitraria o manifiestamente ilegal de un derecho o garantía constitucional, hace cosa juzgada respecto del amparo, dejando subsistente el ejercicio de las acciones o recursos que puedan corresponder a las partes, con independencia del amparo. Finalmente, son procedentes las medidas precautorias o cautelares, en la medida que dentro del proceso de amparo es viable decretar providencias que dispongan medidas de no innovar o la suspensión de los efectos del acto impugnado.

En Brasil la sentencia estimatoria de un mandado de segurança es cosa juzgada inmutable; pero si fuera contrario, la decisión del mandado de segurança no impedirá que el agraviado pueda accionar en tutela de sus derechos y respectivos efectos patrimoniales. Por ello el Supremo Tribunal Federal ha señalado que "la decisión denegatoria del mandado de segurança no hace cosa juzgada contra el demandante, no impide el uso de la acción propia" (Súmula 304).

Así, cuando el fallo rechaza la demanda por cuestiones previas o falta de certeza en cuanto a los hechos, se podrá demandar nuevamente por otra vía procesal. Pero, si los hechos fueran probados y la sentencia deniega la medida, porque el juez considera que no hay un derecho líquido y cierto, se produciría la cosa juzgada material y no podría ser reabierta en otro proceso.

Cabe una medida cautelar a favor del acto impugnado a través de una medida liminar sustentatoria -fumus boni iuris e periculum in mora-, la que perdurará hasta la sentencia de primer grado ${ }^{(41)}$.

\section{Conclusiones}

El proceso constitucional de amparo cumple un rol protagónico en la protección de los derechos de las personas, sobretodo en una región como la latinoamericana que se caracteriza por contar con relativamente nuevos regímenes democráticos que buscan consolidar los fundamentos del Estado constitucional: proteger los derechos humanos como límite a los excesos del poder. Sin embargo, cabe señalar que los desafíos del amparo en un proceso de transición democrática son de naturaleza distinta, al estar vinculado directamente con los problemas democráticos de origen de cada país. En efecto, la naturaleza procesal del amparo tiene en su configuración constitucional, legislativa o jurisprudencial una concepción de la Constitución y del proceso no exenta de la tensión permanente entre la política y el Derecho, como sucede en todo tipo de procesos al afrontar casos difíciles, por cuanto detrás de un gran proceso de amparo, siempre existe una gran cuestión de poder ${ }^{(42)}$.

Por ello, en América Latina encontramos modelos del proceso de amparo que van, por un lado, desde un "noble sueño" para quienes encuentran al proceso de amparo y a la justicia constitucional como mecanismos de obtener justicia, pero muchas veces con el

(41) FERREIRA MENDES, Gilmar, Inócencio MÁRTIRES COELHO y GONET BRANCO, Paulo. Curso de Direito Constitucional. Tercera edición. Sao Paulo: Saraiva, 2008. pp. 541-543.

(42) TRIEPEL, Heinrich. Derecho público y política. Madrid: Civitas, 1986. pp. 33-78. 


\section{César Landa Arroyo}

peligro de su abuso o incluso fraude unilateral de los valores de la Constitución. Y, por otro lado, hasta "una pesadilla" para las élites de siempre que no han necesitado de la justicia constitucional para proteger sus intereses y más bien se preocupan de la inflación de los valores constitucionales e institutos procesales que desarrollan los jueces del amparo para tutelar los derechos fundamentales de los ciudadanos comunes.

En ese arco iris de posibilidades, cada país ha diseñado normativamente su modelo de amparo y más aún lo viene judicializando de distintas formas, en función de la tensión que produce la demanda por los derechos civiles, políticos, económicos y sociales, y, la oferta muchas veces limitada, más aún en épocas de crisis de escasez de oferta de derechos por parte de los poderes públicos y privados, aunque no siempre sea así en las normas constitucionales y legales.

Por ello, en línea de conclusión, se puede señalar que en unos países el amparo puede ser concebido como un recurso procesal dependiente de los procesos ordinarios y en última ratio de los códigos procesales civiles, o, en otros países es entendido como un proceso judicial autónomo con normatividad procesal especial o autónoma en principio; asimismo, para unos su naturaleza puede ser unilateral y de protección subjetiva del derecho fundamental, en tanto su fin sea el favor libertatis o el pro homine, y, para otros su naturaleza puede ser la de un proceso bilateral y de carácter también objetivo, tanto en cuanto hay una relación de interdependencia entre los derechos de libertad y las competencias de la autoridad o de otros particulares, como orientada a la protección de valores constitucionales.
De un lado, el amparo se agota en las normas constitucionales y legales, dejando al juez la labor formalista de la aplicación de las mismas, $y$; de otro lado, se tiene una concepción que hace del amparo un medio de realización de dichas normas mediante la argumentación jurídica, no exenta de establecer reglas procesales, a través de la autonomía procesal que desarrolla el juez creativamente. El amparo en algunos países tutela derechos pre constituidos cuando son violados, por ello se le reconoce al amparo un efecto meramente reparador; pero, en otros, además de ello, surge la tutela mediante el amparo de derechos colectivos e implícitos que emanan de la Constitución y los tratados internacionales de derechos humanos, tutelándolos innovativamente.

Asimismo, en algunos países una relación jurídica se traslada rígidamente a la relación jurídica procesal, de donde emana la legitimación activa y pasiva para actuar, salvo la incorporación de terceros con legítimo interés; mientras que en otros países el modelo deja la relación procesal abierta a la legítima intervención de terceros -amicus curiae-e incluso instituciones garantes de los derechos fundamentales -defensorías del pueblo-. En unos casos, el amparo procede contra la autoridad en la medida que se concibe que la violación a los derechos fundamentales sólo proviene de los poderes públicos -eficacia vertical-, mientras que en otros países además de ello se faculta a interponer el amparo contra particulares -eficacia horizontal-. En consecuencia, mientras que en unos países el amparo cabe contra sentencias judiciales y actos de gobierno; en otros, además de ellos se puede incoar contra normas legales de forma directa cuando son normas autoaplicativas.

Finalmente, se puede señalar que "el noble sueño" del modelo del amparo clásico reposa en una concepción liberal y privatista del proceso vinculada al quehacer de la justicia ordinaria, llevada a cabo en principio por los tribunales o cortes supremas que remontan a duras penas los anclajes del proceso privado. Mientras que "la pesadilla" del amparo moderno es una concepción garantista del proceso, que desarrollan sobretodo los tribunales constitucionales; los cuales en general vienen cumpliendo un rol protagónico en la tutela efectiva de los derechos fundamentales y la defensa de la supremacía constitucional. 